\title{
Congratulations to Professor Czesław Radzikowski
}

\section{PIOTR KUŚNIERCZYK}

Hirszfeld Institute of Immunology and Experimental Therapy, Polish Academy of Sciences, Wrocław, Poland

Professor Czesław Radzikowski, a co-founder of the Polish Society of Experimental and Clinical Immunology in 1975, an honorary member of the Society since 1995 , and honoured with the medal of the Society in 2014, celebrated his $90^{\text {th }}$ birthday on July 17, 2019. Although retired in 2000, he is still active in the Polish Academy of Arts and Sciences (PAU) and remains in good physical and intellectual condition. We wish him many more years of fruitful activity.

Fig. 1. Professor Czesław Radzikowski

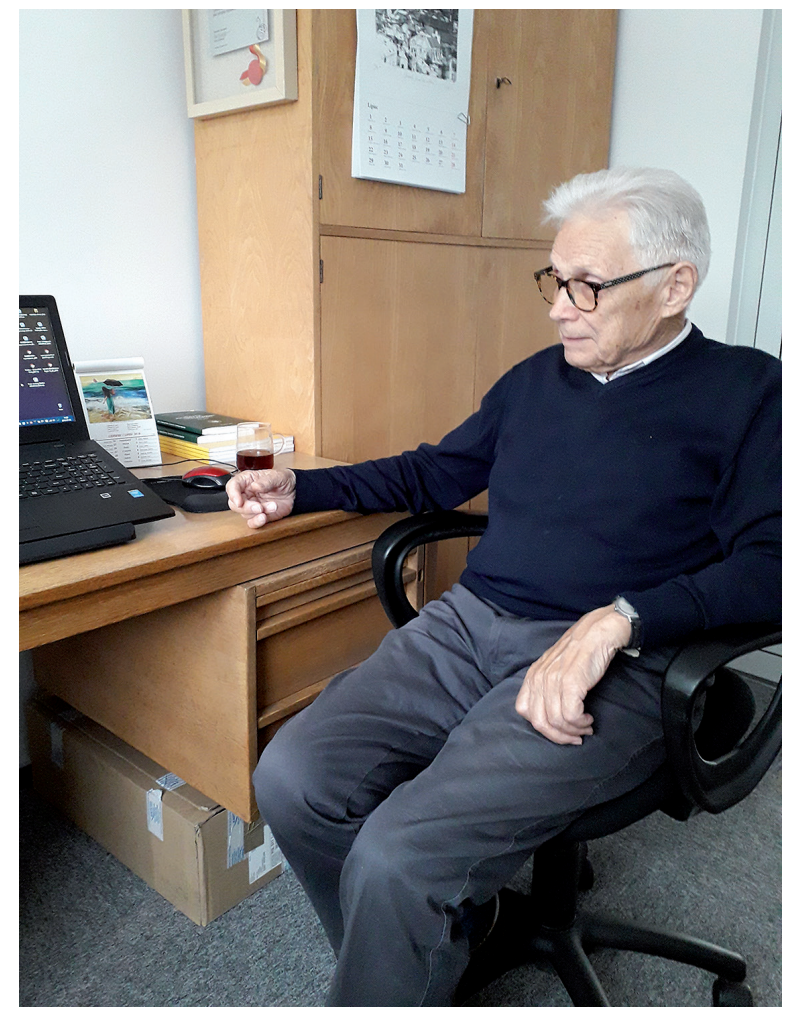

Correspondence: Prof. Piotr Kuśnierczyk, Hirszfeld Institute of Immunology and Experimental Therapy, Polish Academy of Sciences, 12 Rudolfa Weigla St., 53-114 Wrocław, Poland, e-mail: piotr.kusnierczyk@ hirszfeld.pl Submitted: 24.07.2019; Accepted: 25.07.2019 